\title{
Analysis of Steel and Composite Leaf Spring for Vehicle
}

\author{
Ghodake A. P.*, Patil K.N. \\ Department of Mechanical Engineering, SND COE \& RC Yeola, Nashik, India
}

\begin{abstract}
The Automobile Industry has shown keen interest for replacement of steel leaf spring with that of glass fiber composite leaf spring, since the composite material has high strength to weight ratio, good corrosion resistance and tailor-able properties. The present study searches the new material for leaf spring. In present study the material selected was glass fiber reinforced plastic (GFRP) and the polyester resin (NETPOL 1011) [5] is used against conventional steel. A spring with constant width and thickness was fabricated by hand lay-up technique which was very simple and economical. The numerical analysis is carried via finite element analysis using ANSYS software. Stresses, deflection and strain energy results for both steel and composite leaf spring material were obtained. Result shows that, the composite spring has maximum strain energy than steel leaf spring and weight of composite spring was nearly reduced up to $85 \%$ compared with steel material.

This paper describes design and FEA analysis of composite leaf spring made of glass fibre reinforced polymer. The dimensions of an existing conventional steel leaf spring of a light commercial vehicle are taken for evaluation of results.
\end{abstract}

\section{Introduction}

Finite Element analysis tools offer the tremendous advantage of enabling design teams to consider virtually any molding option without incurring the expense associated with manufacturing and machine time. The Ability to try new designs or concepts on the computer gives the opportunity to eliminate problems before beginning production. Additionally, designers can quickly and easily determine the sensitivity of specific molding Parameters on the quality and production of the final part. The leaf spring model is created by modeling software like pro-E, Catia and it is imported in to the analysis software and the loading, boundary conditions are given to the imported model and result are evaluated by post processor.

The different comparative results of steel leaf spring and composite leaf spring are obtained to predict the advantages of composite leaf spring for a vehicle.

\section{FEA (Finite Element Analysis)}

FEA tool is the mathematical idealization of real system. Is a computer based method that breaks geometry into element and link a series of equation to each, which are then solved simultaneously to evaluate the behavior of the entire system. It is useful for problem with complicated geometry, loading, and material properties where exact analytical solution are difficult to obtain. Most often used for structural, thermal, fluid analysis, but widely applicable for other type of analysis and simulation

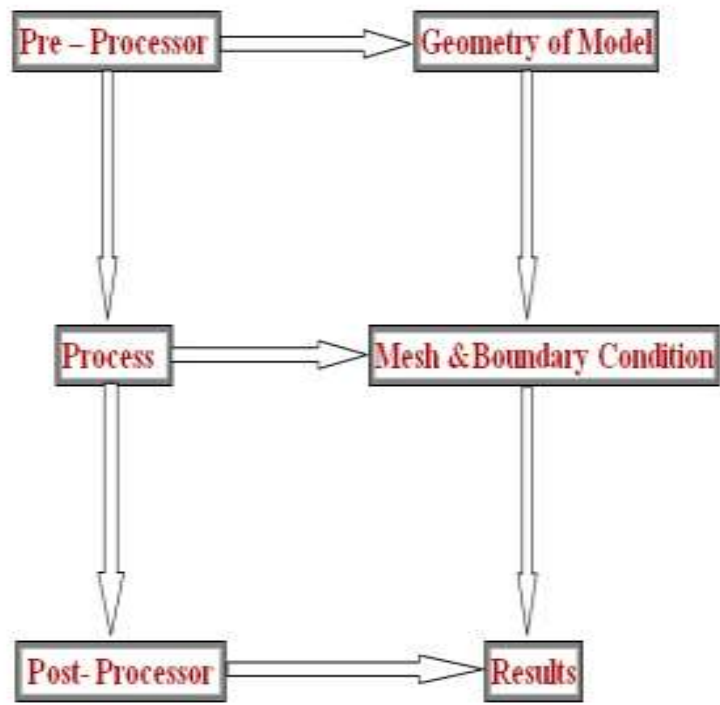

Fig.1.Typical FEA procedures by commercial software 


\section{Materials for Steel leaf spring}

Plain carbon steel, Chromium vanadium steel, Chromium- Nickel- Molybdenum steel, Siliconmanganese steel, are the typical materials that are used in the design of leaf springs. The material selected for steel leaf spring is $65 \mathrm{Si}$. The design parameters selected for steel leaf are listed in table 1.

Table1: design parameters of steel leaf spring

\begin{tabular}{|l|c|}
\hline \multicolumn{1}{|c|}{ Parameters } & Values \\
\hline Material selected & Steel $65 \mathrm{Si7}$ \\
\hline Tensile strength & $1962 \mathrm{~N} / \mathrm{mm}^{2}$ \\
\hline Yield strength & $1470 \mathrm{~N} / \mathrm{mm}^{2}$ \\
\hline Young's modulus(E) & $2 \mathrm{e} 5 \mathrm{~N} / \mathrm{mm}^{2}$ \\
\hline Design stress $\left(6_{\mathrm{b}}\right)$ & $600 \mathrm{~N} / \mathrm{mm}^{2}$ \\
\hline Total length & $1540 \mathrm{~mm}$ \\
\hline Arc height at axle seat & $136 \mathrm{~mm}$ \\
\hline Normal static loading & $2500 \mathrm{~N}$ \\
\hline Available space for spring width & $70 \mathrm{~mm}$ \\
\hline Number of leaves & 01 \\
\hline
\end{tabular}

\section{Materials for Composite leaf spring}

Based on the specific strain energy of steel spring and some composite materials, the E-glass/epoxy is selected as the spring material. The parameters for composite leaf spring material are listed in table 2 .

Table2: parameters of composite leaf spring

\begin{tabular}{|l|l|}
\hline \multicolumn{1}{|c|}{ Properties } & \multicolumn{1}{c|}{ Values } \\
\hline Tensile Strength & $900 \mathrm{~N} / \mathrm{mm}^{2}$ \\
\hline Compressive strength & $450 \mathrm{~N} / \mathrm{mm}^{2}$ \\
\hline Poisson ratio $(\mathrm{T})$ & 0.217 \\
\hline Mass density $(\rho)$ & $2.6 \mathrm{e}-10 \mathrm{~kg} / \mathrm{mm}^{3}$ \\
\hline Flexural strength $(\sigma)$ & $1200 \mathrm{~N} / \mathrm{mm}^{2}$ \\
\hline Flexural modulus(E) & $40000 \mathrm{~N} / \mathrm{mm}^{2}$ \\
\hline
\end{tabular}

\section{Strain Energy}

The stored elastic strain energy in a leaf spring varies directly with the square of maximum allowable stress and inversely with the modulus of elasticity both in the longitudinal and transverse directions according to

Where,

$$
\mathrm{S}=\sigma_{\mathrm{t}}^{2} / 2 \rho \mathrm{E}
$$

$S$ is the strain energy,

$\sigma_{\mathrm{t}}$ is the allowable stress,

$E$ is the modulus of elasticity and

$\rho$ is the density.

\section{Geometry of leaf spring}

Figure 2 shows the imported geometry of mono leaf spring. This geometry has been created in Solid works by taking the dimensions from the paper. [5]

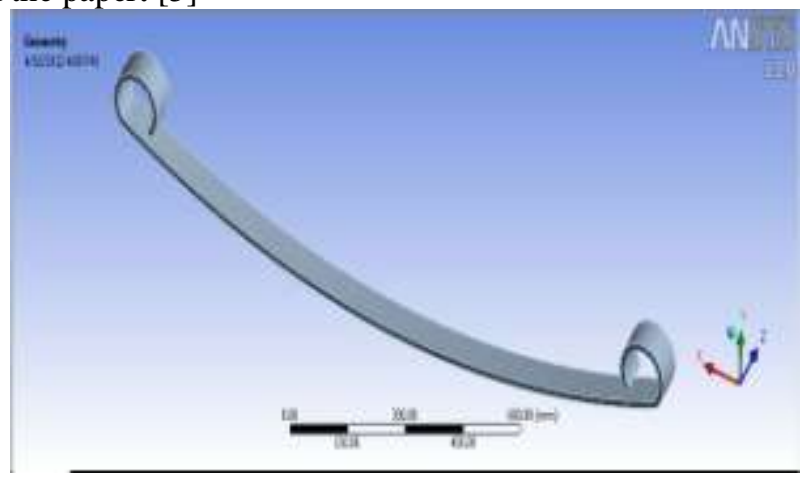

Fig.2. 3-D Model of leaf spring 
Figure 3 shows the 3D model of leaf spring with camber of leaf spring. Total length of leaf is $1540 \mathrm{~mm}$ and $136 \mathrm{~mm}$ is the arc height at axel seat.

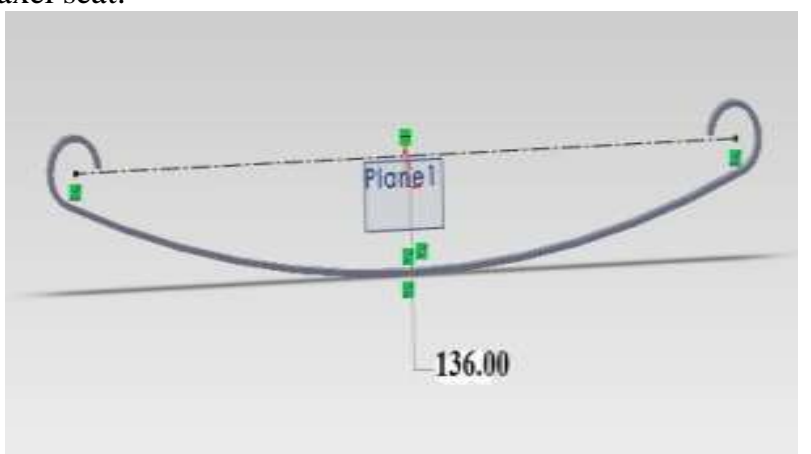

Fig.3. 3-D Model of leaf spring showing camber $(136 \mathrm{~mm})$ of leaf spring.

\subsection{Meshed model of leaf spring}

Meshing is nothing but the descritization of object into the small parts called as the element.this analysis is limited upto the 2D analysis therefore only quard and triangular elements are used. Figure 4 shows the meshed model of mono leaf spring with an element size of $5 \mathrm{~mm}$ brick mesh. Previous Studies show that the best results are obtained using brick mesh. Considering the concept of grid independence it is been found that this is the best suited size of mesh hence this size of mesh has been selected.

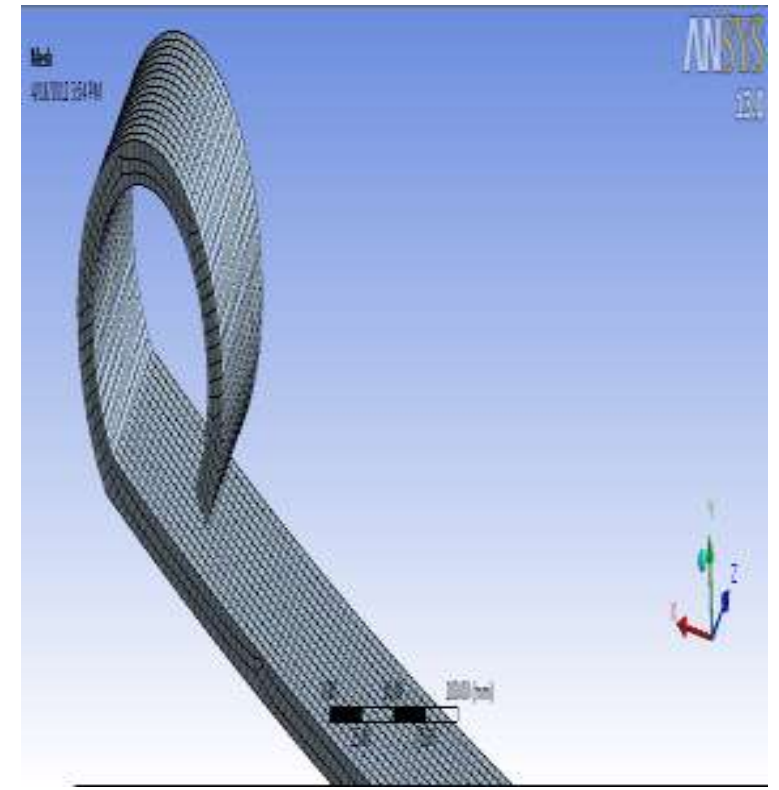

Fig.4. Meshed model of leaf spring.

\subsection{Loading \& Boundary Conditions:}

\subsubsection{Fixed Support}

Fixed support has restriction to move in $\mathrm{X}$ and $\mathrm{Y}$ direction as well as rotation about that particular point. For the leaf spring analysis one eye end of the leaf spring is fixed to the chassis of the vehicle and the fixed support at another eye end of the leaf spring model. So this eye end of the leaf spring cannot move in any of the directions i.e. all the degrees of freedom are blocked

\subsubsection{Cylindrical support}

As there is shackle provided at other end of the leaf spring because of which the leaf spring only translates in one plane and other movements i.e. degree of freedom are blocked. So with the reference of this a cylindrical support is applied to the other eye end of leaf spring model. This support allows the movement of the leaf spring in $\mathrm{X}$ axis, rotation about $\mathrm{Z}$ axis and fixed along $\mathrm{Y}$ axis. 


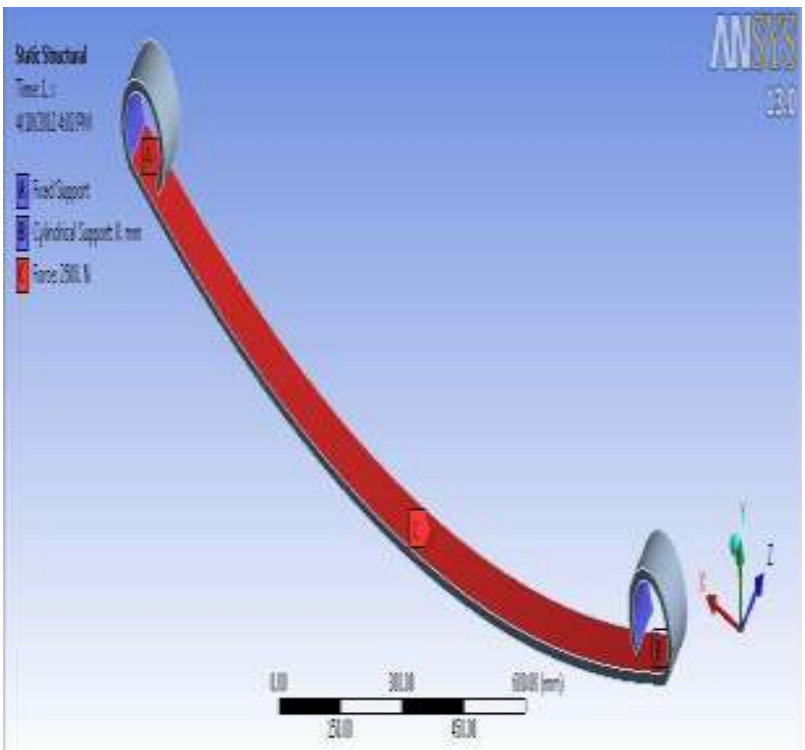

Fig.5. Fixed support and cylindrical support with load

Since the load is uniformly distributed on the leaf spring, here in this study uniformly distributed load of $2500 \mathrm{~N}$ is applied on the leaf spring model. The uniformly distributed load is shown in figure 6.

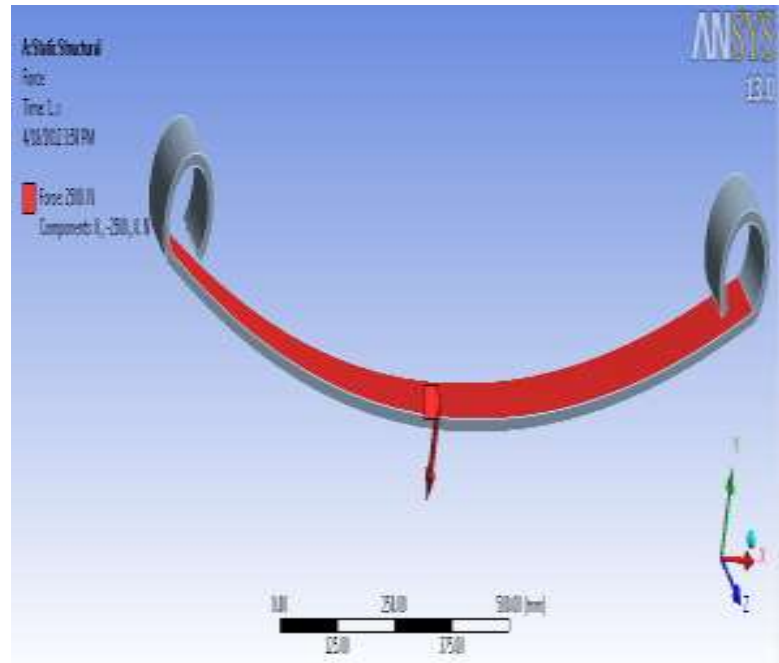

Fig. 6. Uniformly distributed load of $2500 \mathrm{~N}$ on the leaf spring

7.1 Total Deflection:

\section{Results and Discussion}

\subsubsection{Deflection for Steel leaf spring}

Figure 7 shows the deflection of steel leaf spring under the application of $2500 \mathrm{~N}$ load. The maximum deflection is at the centre of the leaf spring its maximum value is $1.78 \mathrm{~mm}$. Red zone indicates the area of maximum deflection and blue zone indicates the area of minimum deflection, which are shown by probe. 


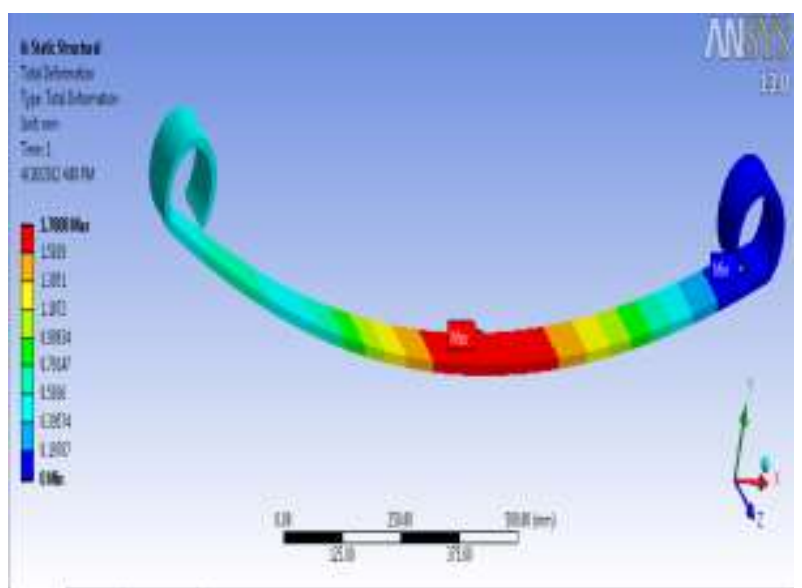

Fig. 7. Total deformation of steel leaf spring.

\subsubsection{Deflection for Composite leaf spring}

Figure 8 shows the deflection of composite leaf spring under the application of $2500 \mathrm{~N}$ load. The maximum deflection is at the centre of the leaf spring its maximum value is $17.72 \mathrm{~mm}$. Red zone indicates the area of maximum deflection and blue zone indicates the area of minimum deflection which is at the eye end.

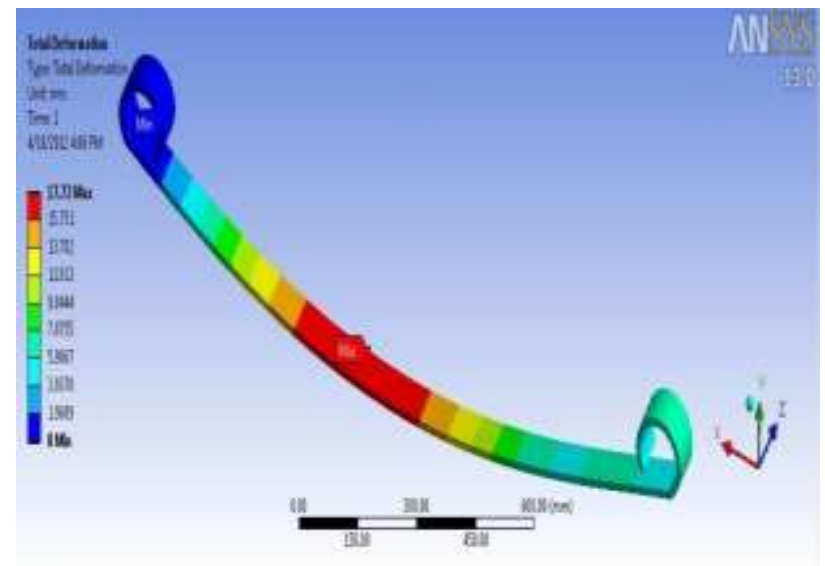

Fig. 8. Total deformation of Composite leaf spring

\subsection{Strain Energy}

\subsubsection{Strain Energy for steel leaf spring}

Figure 9. Shows the strain energy in steel leaf spring under the application of $2500 \mathrm{~N}$ load. For this loading condition $1.03 \mathrm{MJ}$ strain energy is obtained and it the maximum value of strain energy for steel leaf spring for $2500 \mathrm{~N}$.

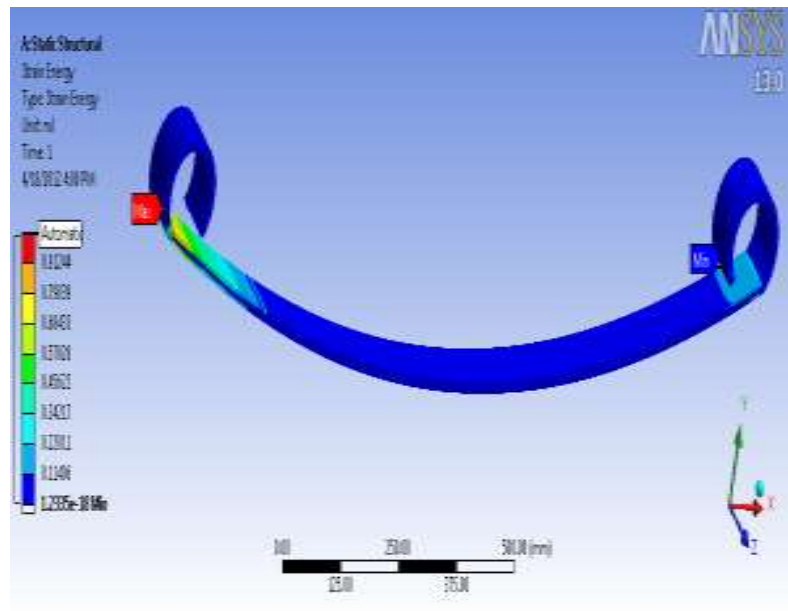

Fig.9 Strain energy for steel leaf spring 


\subsubsection{Strain Energy for Composite leaf spring}

Figure 10 shows the strain energy in Composite leaf spring under the application of $2500 \mathrm{~N}$ load. For this loading condition $18.90 \mathrm{MJ}$ strain energy is obtained and it the maximum value of strain energy for composite leaf spring for $2500 \mathrm{~N}$.

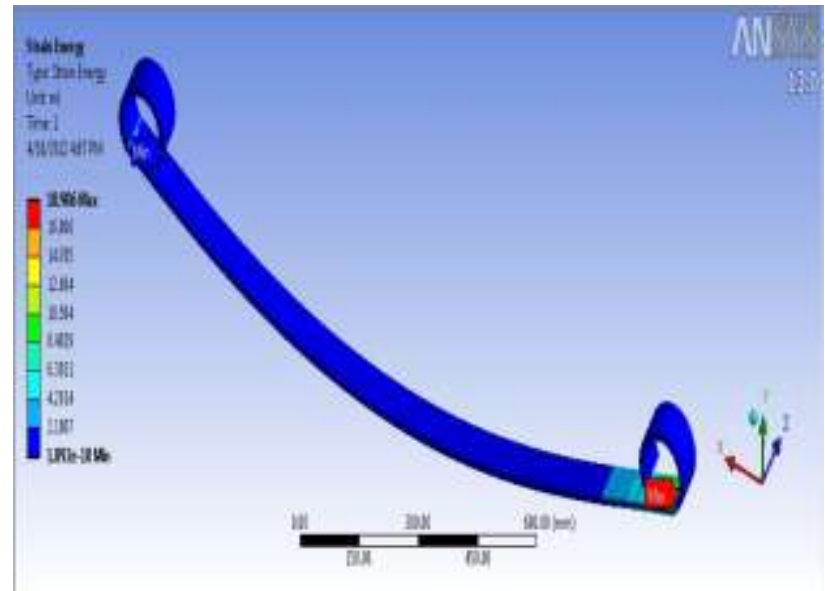

Fig.10. Strain energy for Composite leaf spring

\subsection{Stress}

\subsubsection{Stress for Steel leaf spring}

Figure 11 shows the equivalent von-Mises stress induced in steel leaf spring under the action of $2500 \mathrm{~N}$ load. The maximum stress is induced at the fixed eye end of the leaf spring its maximum value is $99.95 \mathrm{~N} / \mathrm{mm}^{2}$. Red zone indicates the area of maximum stress and blue zone indicates the area of minimum stress.

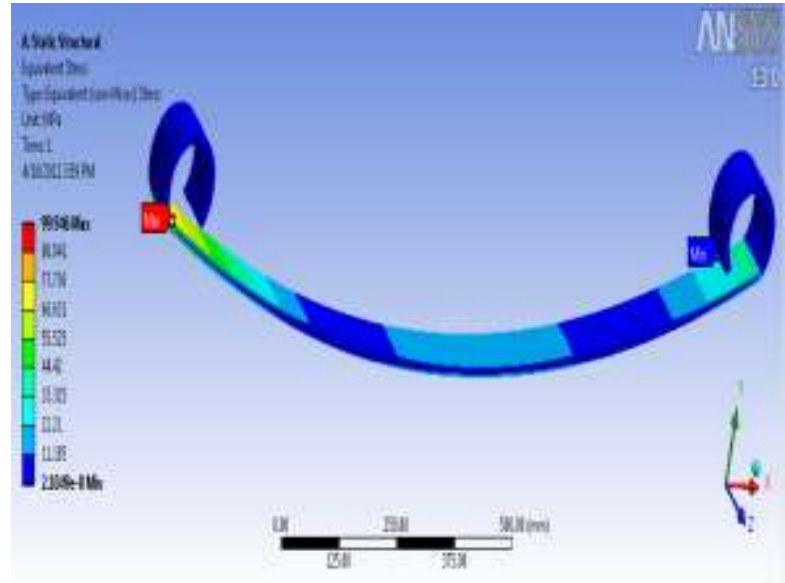

Fig.11 Stress of Steel leaf spring

\subsection{Result Tables}

The tables 3 shows the comparative results both Steel and composite leaf spring.

Table3: Results of Steel and composite material

\begin{tabular}{|c|c|c|c|c|c|c|}
\hline \multirow{2}{*}{ Load(N) } & \multicolumn{2}{|c|}{ Deformation(mm) } & \multicolumn{2}{c|}{ Strain Energy (MJ) } & \multicolumn{2}{c|}{ Stress(N/mm $\mathbf{m}^{\mathbf{2}}$} \\
\cline { 2 - 7 } & Streel & Composite & Streel & Composite & Streel & Composite \\
\hline 500 & 0.36 & 3.54 & 0.04 & 0.75 & 19.98 & 19.29 \\
\hline 1000 & 0.71 & 7.08 & 0.16 & 3.02 & 39.97 & 38.57 \\
\hline 1500 & 1.07 & 10.63 & 0.36 & 6.80 & 59.96 & 57.86 \\
\hline 2000 & 1.42 & 14.17 & 0.65 & 12.09 & 79.95 & 77.15 \\
\hline 2500 & 1.78 & 17.72 & 1.026 & 18.90 & 99.94 & 96.42 \\
\hline
\end{tabular}


Table 4: Weights of Steel and composite material

\begin{tabular}{|c|c|c|}
\hline Leaf spring type & Steel & Composite \\
\hline Weight $(\mathrm{kg})$ & 15.86 & 2.97 \\
\hline
\end{tabular}

\subsubsection{Stress Composite leaf spring}

Figure 12 shows the equivalent von-Mises stress induced in composite leaf spring under the application of $2500 \mathrm{~N}$ load. The maximum stress is induced at the fixed eye end of the leaf spring its maximum value is 96.424 $\mathrm{N} / \mathrm{mm}^{2}$.

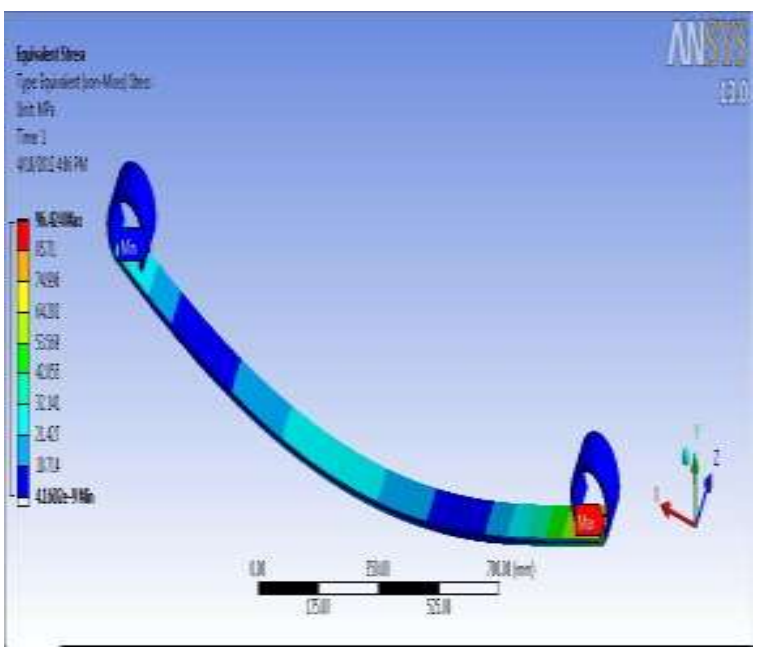

Fig. 12 Stress of composite leaf spring

7.5 Graphical comparison for both steel and composite material 7.5.1 Load Verses Deformation

Figure 13 shows the comparison of load verses deformation of both steel and composite leaf springs. It is found that the deformation in composite leaf spring is higher than steel leaf spring for the given loading conditions.

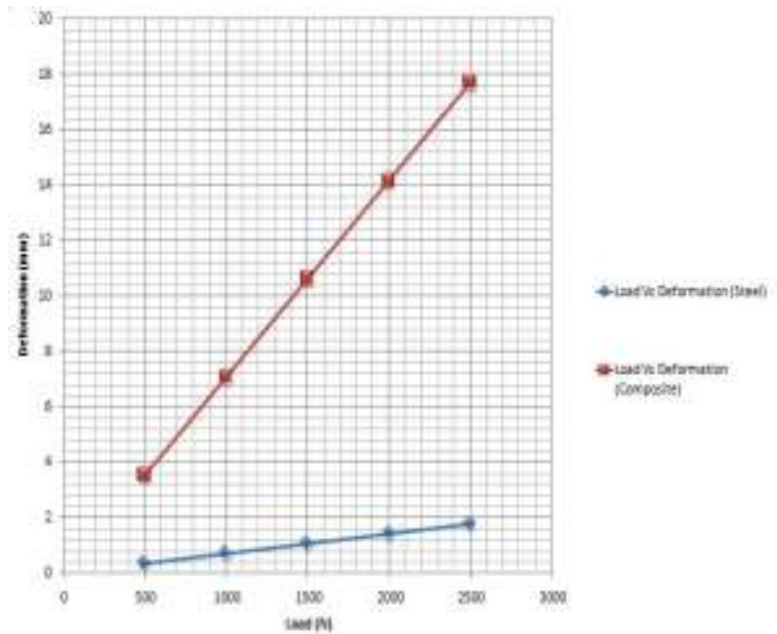

Fig 13. Graph of Load Verses Deformation

\subsubsection{Load Verses Strain Energy}

Figure 14 shows the comparison of load verses strain energy of both steel and composite leaf springs in the above graph the load is taken on the $\mathrm{x}$-axis. Whereas the strain energies for steel and composite material are taken on y-axis. From the graph it is we can see the variations in the respective strain energies of both materials. 


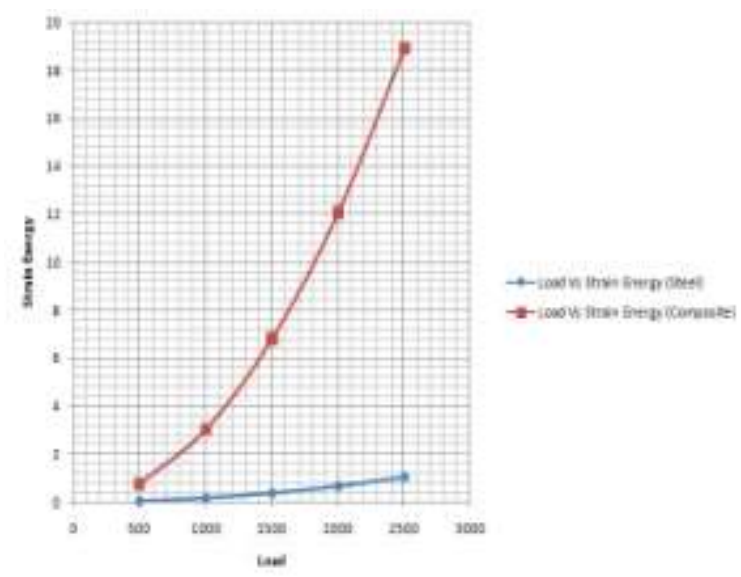

Fig. 14 Graph of Load Verses Strain Energy

It is found that the strain energy for composite leaf spring is higher than steel leaf spring.

\subsubsection{Load Verses Stress}

Figure 15 shows the comparison of load verses stress of both steel and composite leaf springs. It shows the load is taken on the $\mathrm{x}$-axis. Whereas the stress for steel and composite material is taken on $y$-axis. Observation of the graph indicates the difference level of stress of two different materials.

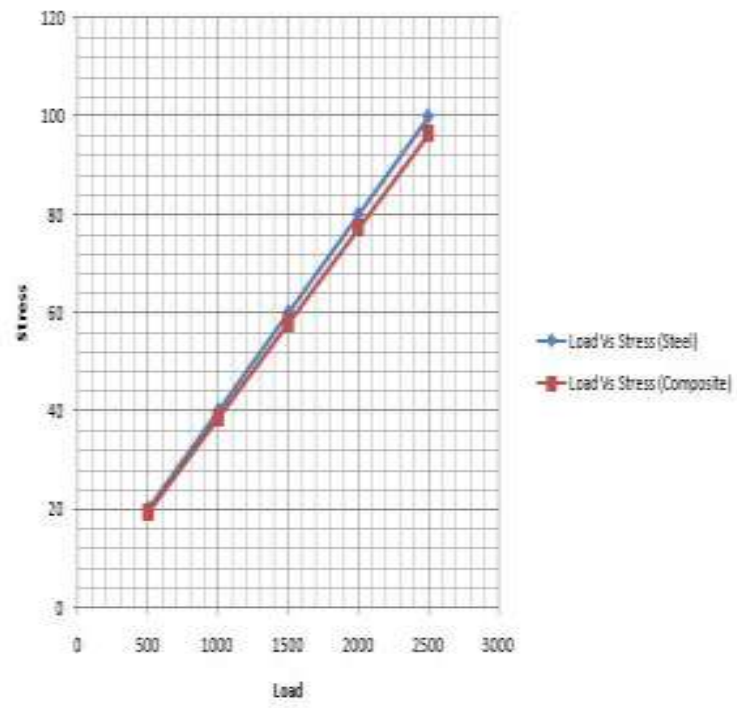

Fig. 15 Graph of Load Verses Stress

It is found that the there is not much variation in stress for composite leaf spring is higher than steel leaf spring.

\subsubsection{Comparison of weights}

Figure 16 shows a Bar- Chart drawn for the comparison of weight of both steel and composite leaf springs. The bar chart drawn below shows the comparisons in leaf spring weight $(\mathrm{Kg})$ in case of steel and composite material. Blue bar is the weight of steel leaf spring whereas red bar shows the weight of composite leaf spring. From this comparison of bar chart it is easily observed that the weight reduction in leaf spring. For steel leaf spring weight is $15.86 \mathrm{~kg}$ and for composite leaf spring it is $2.97 \mathrm{~kg}$. 


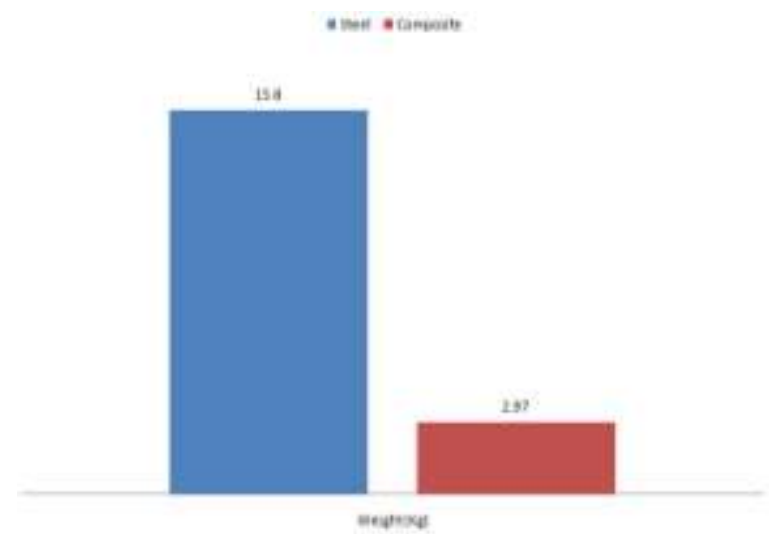

Fig. 16 Comparison of weights in steel and composite

\section{Conclusion:}

The 3-D modeling of both steel and composite leaf spring is done and analyzed A comparative study has been made between composite and steel leaf spring with respect to Deflection, strain energy and stresses. From the results, It is observed that the composite leaf spring is lighter and more economical than the conventional steel spring with similar design specifications. It is observed that the weight reduction of mono leaf spring is achieved up $84.94 \%$ in case of composite than steel.

It can be easily observed that material having lower modulus and density will have a greater specific strain energy capacity. The introduction of composite materials was made it possible to reduce the weight of the leaf spring without any reduction on load carrying capacity and stiffness. Since the composite materials have more elastic strain energy storage capacity and high strength-to-weight ratio as compared to those of steel.

It is observed that the composite material shows more deflection and strain energy than that of steel material.

\section{References:}

[1] Introduction to Finite elements in engineering, T.R. Chandrupatla and A.D. Belegunde, 1997, Second Edition. Prentice-Hall International Inc.

[2] Optimal Design of a Composite Leaf Spring using Geneti Algorithms, Rajendran, I., Vijayarangan, S. Int. Jr. of Computer and Structures 79 2001: pp. $1121-1129$

[3] Design and Analysis of a Composite Leaf Spring, Rajendran, I., Vijayarangan, S. Journal of Institute of Engineers India 822002 : pp. $180-187$.

[4] Mono Composite Leaf Spring for Light Weight Vehicle, Gulur Siddaramanna SHIVA SHANKAR*, Sambagam VIJAYARANGAN Mechanical Engineering Department, PSG College of Technology, Coimbatore-641004, India Received 20 June 2005; accepted 07 April 2006

[5] Modelling and Analysis of AComposite Leaf spring under the Static Load Condition by using FEA, M.M. Patunkar,D.R.Dolas 2011. 